УДК 902

https://doi.org/10.24852/2587-6112.2020.5.17.24

\title{
ОСОБЕННОСТИ ИСПОЛЬЗОВАНИЯ КОСТИ, КАК ТОПЛИВА ДЛЯ КОСТРОВ, В ВЕРХНЕМ ПАЛЕОЛИТЕ РУССКОЙ РАВНИНЫ
}

\author{
(C) 2020 г. Т. О. Петровичева, Е. Я. Зубавичус
}

На материале исследований стоянок среднего и позднего Верхнего палеолита Русской равнины показано распространение и вариации использования кости в качестве топлива. Эти практики сопоставлены с этнографическими данными. Обобщены результаты предыдущих экспериментов по установлению бытовых характеристик топлива из кости. Установлено, что в качестве топлива могли использоваться только кости с сохранившимся костным мозгом, которые разжигались при помощи дерева. Добыча и использование таких костей было одним из механизмов адаптации человека к условиям холодного климата при отсутствии достаточного количества древесины. Выводы дополнены и проверены проведением собственных экспериментов.

Ключевые слова: археология, верхний палеолит, Русская равнина, Виллендорфскокостенковсковская культура, стратегии адаптации.

\section{FEATURES OF THE USE OF BONES AS FUEL FOR CAMPFIRES IN THE UPPER PALEOLITHIC OF THE OF RUSSIAN PLAIN}

\section{T.O. Petrovicheva, E. Y. Zubavichus}

The paper describes the distribution and variation of the use of bones as fuel on the basis of a study of Middle and Late Upper Paleolithic sites of the Russian Plain. These practices are compared with ethnographic data. The results of previous experiments to establish household characteristics of bone fuel are summarized. It was established that only bones with preserved bone marrow, which were fired with wood, could be used as fuel. The extraction and use of such bones was one of the mechanisms of human adaptation to cold climatic conditions in the absence of sufficient amounts of wood. The conclusions are supplemented and verified by conducting own experiments.

Keywords: aarchaeology, Upper Paleolithic, Russian Plain, Willendorf-Kostenki culture, adaptation strategies.

Время использования кости как топлива для костра приходится в основном на среднюю и позднюю пору ВП, хотя заполнение очагов костным углем встречается и в более позднее время. Эта эпоха принадлежит к последнему ледниковому периоду. Начало средней поры верхнего палеолита приходится на LGM. В интервале 26500-19000 л. н. происходило похолодание. Затем последовало относительное потепление. Отчасти оно совпало с поздним периодом ВП: 19000-10000 л. н.

Во время LGM территории, заселенные человеком, представляли собой перегляционную лесотундру, местами перемежающуюся с перегляционными степями (Амирханов, 2000, c. 58). Климат был сухим и холодным. Одной из культур, существовавших в таких условиях, была Виллендорфско-костёнковская культура, представлявшая собой сообщества подвижных охотников на крупных млекопитающих (в основном мамонтов). Памятники этой культуры обнаружены в бассейне Оки - это группа разновременных памятников Зарайск A-D, на Среднем Дону - Костёнки $1 / 1$, в долине Сейма - Авдеевская стоянка и в Белорусском
Поднепровье - стоянка Бердыж. На всех этих памятниках обнаружен костный уголь.

Приступая к анализу материалов конкретных памятников, отметим, что это лишь выборка из множества памятников, на которых был обнаружен костный уголь, которая определена сферой наших научных интересов.

Наиболее ранним памятником Виллендорфско-костёнковской культуры являются Костёнки 1/1 (24-21 тыс. л. н.) (Человек и мамонт..., 2019, с. 55-56). Здесь обнаружены очажные ямы диаметром до 1 м, заполненные костным углем. В одном из очагов найден древесный уголь (Крауфорд, 2018). Сама возможность его находки объясняется тем, что летние температуры были достаточно высоки для существования в этом регионе деревьев и кустарников (Амирханов, 2000, c. 58). Однако заполнение очагов костным углем преобладает. Мы связываем это с тем, что древесины было недостаточно для полноценного костра, но при этом для костей была необходима древесная растопка (подробнее об этом будет сказано ниже). На полу земля- 
нок, из которых состоял комплекс, обнаружены россыпи костного угля. По предположению Н.Д. Праслова, поддержанному рядом других ученых, уголь накрывали шкурами и на них грелись (Человек и мамонт..., 2019, с. 47). Уголь также мог служить как абсорбент для воды и поддерживать сухость помещения (Человек и мамонт..., 2019, с. 47).

Зарайск А представляет собой стоянку охотников на мамонтов, принадлежащую к общности культур восточного граветта. Для первых двух этапов жизни стоянки (23-21 тыс. л. н.) характерны вытянутые в линию очаги костенковско-авдеевского типа (Человек и мамонт..., 2019, с. 23.). Для этого типа очагов свойственно иметь размер более метра в диаметре и большую глубину, достигающую 30-70 см. Мощность слоя костного угля достигала более $10 \mathrm{~cm}$. В слое памятника встречались многочисленные вкрапления и прослойки костного угля, что свидетельствует об использовании костного топлива в больших объемах. Очаги находились внутри жилых конструкций.

Авдеевская стоянка датируется временем 23-20 тыс. л. н. (Булочникова, 2008, с. 64). Здесь также присутствуют расположенные в ряд очаги (7 шт.), существовавшие одновременно и заполненные костным углем.

На стоянке Бердыжская или Подлужье I (23-24 тыс. л. н.) обнаружено два жилища (Загорульский, 2001), внутри которых найдены пятна костного и древесного угля. Предположительно, это были очаги.

Обобщая, можно заключить, что на всех стоянках виллендорфско- костёнковской культуры очаги заполнены преимущественно костным углем. Иногда встречает древесный уголь. Вероятно, древесина использовалась на всех стоянках для растопки, но не была зафиксирована из-за плохой сохранности и своего незначительного количества. Таким образом, в пределах одной культуры мы встречаем вариации использования костного топлива. Так, в Костёнках 1/1 и Подлужье I уголь высыпали на пол жилища, а в Зарайске А выгребали в приочажные ямки или ссыпали в зольники.

На юге в Брянском Подесенье памятники виллендорфско-костёнковской культуры сменяются стоянками павловско-хотылёвской культуры, представленной памятниками Хотылево II и Гагарино. Виллендорфскокостёнковская и павловско-костёнковская культуры составляют виллендорфско-павловско-костёнковское единство днепро-донской историко-культурной области. Памятник Хотылево II (на реке Десне) объединяет под одним названием стоянки A-D. Он синхронен Костёнкам 1/1 и Авдеево. На Хотылево II обнаружены три жилые конструкции, три очага и две ямы, которые тоже предположительно интерпретируются как очаги (Гаврилов, 1998, с. 177). Очаги находились по центру внутри двух жилых конструкций. В третьем «жилище» на полу найдено только пятно золы. Очаги были более метра в диаметре, глубиной 10-30 см и заполнены костным углем. Мощность слоя угля в очаге 3 составляла $40 \mathrm{~cm}$, что превышает глубину очага. В скоплениях костного угля обнаружен древесный дендрит ${ }^{1}$, «что говорит о растопке костей при помощи дерева (кустарников)»². Очаг 2 был закрыт плечевой костью мамонта и несколькими позвонками. Аналогичная практика присутствует на Зарайске-А, где был обнаружен очаг, закрытый лопаткой мамонта. В северо-западной половине очага 3 сложены позвонки и ребра волка. Сложно сказать, связано это с утилитарными или ритуальными целями. На стоянке Гагарино (левый берег Дона) также обнаружено обилие костного угля - след долговременного обитания.

На западе зона виллендорфско-костёнковской культуры граничит с днепро-деснинской группой стоянок охотников на мамонтов. На стоянке Юдиново, принадлежащей к последней, в заполнении очагов обнаружено большое количество костного угля (Хлопачев, 2015 , c. 135).

Во время поздней поры ВП холодный климат смягчается, наступает интерстадиал поздневалдайского оледенения. Появляются елово-березово-сосновые леса и разнотравно-злаковые луга (Амирханов, 2000, с. 59). Зарайск А продолжает существовать, сохраняя традицию костров на основе топлива из кости. На среднем Дону появляются стоянки Костёнки 11/II и Костёнки 21/III. В жилищах Костёнок 11/II было найдено большое количество костного угля и небольшая линза древесного угля (Человек и мамонт..., 2019, с. 184, 227). В Костёнках 21/III преобладал древесный уголь.

На стоянке Каменная Балка I (14 тыс. л. н.) в углубленных очагах, расположенных по одной линии, был найден костный уголь.

Дендрит - сложнокристаллическое образование, имеющее древовидную структуру.

2 Цит. по письму К.Н. Гаврилова. Информация любезно сообщена в личном письме. 
Часть очагов находились в наземных жилых объектах (Леонова и др., 2015, с. 53).

Использование кости как топлива было распространено на широкой территории перегляционных тундр ВП. Мы интерпретируем это как модель приспособления к суровым холодам в условиях недостатка древесины. Доказательством служит тот факт, что так поступали представители различных культур, обитающих, однако, в сходных природных условиях. Этнографические данные также подтверждают, что в условиях холодного климата и при отсутствии дерева люди вынуждены использовать другие типы топлива. Эскимосы, живущие в границах вечной мерзлоты, использовали для отопления китовый жир, а живущие южнее в лесной зоне субарктики индейцы уже нет (Файнберг, 1991, c. 184). В ВП кости для костра могли добывать не только на охоте, но и из аккумулятивных костищ $^{3}$, где в условиях холодного климата костный мозг сохранялся длительное время.

Основываясь на этнографических исследованиях $\mathrm{XIX}-\mathrm{XX}$ веков, можно разделить причины использования костного топлива на три группы: сжигание ради бытовых целей (утилизация отходов), использование как топлива и ритуальное сжигание. К первой группе относятся юкагиры, которые сжигали лишние кости при оставлении места зимовки или когда костей скапливалось слишком много. Однако в этих случаях костный мозг предварительно извлекался для употребления в пищу или для отдельного использования в качестве топлива (Крейнович, 1972, с. 76, 85-86). Ко второй - чукчи. При отсутствии древесины они устраивали “кухни” на горящих костях, которые поливали жиром, чтобы лучше горели (Крушанов, 1987, с. 78). Представления о возможности использования костей как топлива сохранились в верованиях ительменов, которые принимали дымящие горы за костры мертвых предков, жгущих китовые кости (История и культура ительменов, 1990, с. 139). К третьей - алтайцы, с оговоркой, что они относятся к иному хозяйственно-культурному типу (Торушев, 2007, c. 127-128).

Важнейшим источником информации о бытовых свойствах костного топлива является эксперимент. Интересны результаты ряда междисциплинарных исследований, опубликованных сотрудниками Националь-

\footnotetext{
Естественные скопления костей погибших животных, осевшие в природных углублениях.
}

ного центра научных исследований Франции (CNRS) (Sandrine et al, 2002, p. 51). Костаманьо Сандрин, Изабель Тери-Паризо и другие специалисты провели серию экспериментов, чтобы определить тафономические ${ }^{4}$ последствия использования кости в качестве топлива. Исследователи сжигали разные виды костей: трубчатые, губчатые и др., сухие и свежие, крупные и мелкие - для поиска взаимосвязи между типом костного топлива и внешним видом получившегося костного угля. Как было установлено, для того чтобы кости загорелись, требовалась довольно высокая температура, поэтому была необходима предварительная древесная растопка (Sandrine et al, 2002, p. 52). Замеры температуры горения костного топлива в лабораторных условиях дали диапазон $605-805^{\circ} \mathrm{C}$, при этом основным фактором, влияющим на температуру, была общая масса горящего костного топлива. Замеры температуры в открытых очагах дали диапазон между 561 и $692^{\circ} \mathrm{C}$. Было установлено, что на максимальную температуру в открытом костре существенно влияют атмосферные факторы (Sandrine et al, 2010, p. 174). Вдобавок к этому, на горючие свойства влияло количество жира в определенной части кости. Кости проксимальных конечностей горели лучше из-за большего содержания жира в губчатых элементах. Также оказалось, что фрагментированные кости горят хуже целых из-за слишком быстрого вытекания костного мозга. Сухие кости горели хуже, чем свежие. (Sandrine et al, 2002, p. 55-56). Интерпретация реальных фрагментов обгорелых костей, найденных среди угля, на Зарайске-А свидетельствует, что использовались только свежие кости, но они могли быть как целые, так и фрагментированные (Амирханов, 2009, c. 371$)$.

Из этих наблюдений был сделан вывод, что для использования в качестве топлива лучше всего подходят губчатые кости, поскольку в них содержится большое количество жира, который сложно извлечь для использования в других целях (например, в пищу) (Sandrine et al, 2002, p. 60). Эту особенность отметили и жители ВП. Данные археологии подтверждают существование отбора костей для сжигания. Х.А. Амирханов пишет, что на Зарайске найдено относительно мало позвонков, тазо-

Тафономия - изучает закономерности процессов захоронения и образования местонахождений ископаемых остатков организмов, в данном случае костных. 
вых и трубчатых костей. Он сделал предположение, что они использовались для костров. Отбор костей также присутствовал на Хотылево 2. В очаге 2 найдены позвонки и лопатка мамонта, в очаге 3 - позвонки и ребра волка. В яме 7 , расположенной близко к очагу 1 , найдена одна из таких групп - № 3 с лопатками мамонта. Результаты наших экспериментов также показали, что горят лучше всего трубчатые и губчатые кости.

Рассмотрим наши эксперименты. Всего было сделано четыре тестовых костра. Целью экспериментов было установить:

1. возможно ли разжечь кости без древесины;

2. какой тип костей наиболее пригоден (трубчатые, губчатые, плоские и смешанные);

3. как влияет состояние костей на горение (разбитые или целые, сухие или свежие).

Основной метод - наблюдение.

В экспериментах использовались кости с различными характеристиками: сухие говяжьи, птичьи трубчатые с костным мозгом (курицы), свежие говяжьи без костного мозга, говяжьи хрящи, свежие говяжьи кости с костным мозгом. Кости по отдельности помещались в тестовые костры для наблюдения за их горением. Сжигание костей во всех случаях производилось под открытым небом в мангале (в рамках данного эксперимента наличие очага не обязательно). Для растопки использовалась древесина.

\section{Результаты:}

1. Разжечь кости без древесной растопки (при помощи костяного жирника) не удалось. Для того чтобы кости разгорелись, необходимо наличие высокой температуры на всей массе топлива.

2. Влияние типа костей на горючие свойства:

- Свежие трубчатые птичьи кости (с костным мозгом) не давали видимого пламени. Это объясняется тем, что птичьи кости содержат мало жира. Менее чем за час кости изменили цвет на пепельно-белый. В конце от них остался костный уголь: тонкие хрупкие потрескавшиеся стенки.

- Пламя на свежих говяжьих костях без костного мозга (очищенные от мяса, разбитые, немного просушенные у костра) появилось на поверхности через двадцать минут после помещения в костер. Горение было нестабильным и неустойчивым к ветру. В течение часа кости горели, затем растрескались до твердо- го угля. Затем кости тлели около 30 минут без светового эффекта (покраснения).

- Хрящи разгорались довольно быстро менее 10 минут и горели устойчиво в течение полутра часов.

- Кости свежие с костным мозгом загорелись за 10 минут. При этом пламя наблюдалось в нижней части кости, поскольку горел именно костный мозг, который проникал туда через микротрещины, образовавшиеся при горении. Ярче всего горела губчатая часть кости, в которой образовались наиболее широкие каналы. При извлечении отдельной кости из огня горение продолжалось достаточно устойчиво (рис. 1). Примерно спустя час горения кость растрескалась и распалась, в результате можно было наблюдать горение костного мозга внутри кости. Горение костного мозга продолжалось ещё около 30 минут. Кость горела дольше и ярче, чем хрящ (рис. 1).

3. Влияние состояния костей:

- Сухие кости не удалось разжечь, но под воздействием костра они превращаются в костный уголь. Произошло изменение внешнего вида: кости почернели, обуглились, растрескались.

- Лучше всего горели свежие губчатые и трубчатые кости с костным мозгом, очищенные от мяса (рис. 1).

Основным горючим элементом в кости является жир, содержащийся в костном мозге, а не кость сама по себе. Жир составляет 35-60\% от костного мозга (Мандро, Федоренко, 2013.) Физическое обоснование возможности горения кости - капиллярный эффект или волосность. Растопленный костный мозг поднимается по канальцам в пористой структуре кости. Этим фактором объясняются различия в интенсивности горения у разных типов кости. Сухие кости почти не горят из-за отсутствия костного мозга. Губчатые кости имеют пористую структуру и достаточно большое количество канальцев, через которые костный мозг попадает на поверхность и сгорает. Трубчатые части кости содержат ещё большее количество костного мозга во внутренней полости. Однако во время горения костный мозг внутри кости закипает, что приводит к растрескиванию и разрушению кости из-за внутреннего давления, в результате чего костный мозг вытекает. Быстрым вытеканием костного мозга объясняется и худшее горение фрагментированных костей по сравнению с целыми, которое было зафиксирова- 
но французскими коллегами (Sandrine et al, 2002, p. 56). По этой причине губчатые кости в ряде случаев действительно горят лучше, чем трубчатые, несмотря на сравнительно меньшее содержание костного мозга. Другие отходы от разделки туши и охоты (хрящи, высохшие кости, кости птиц) могли добавляться для массы. Наиболее эффективные показатели кости давали, находясь в мощном костре.

Процесс разжигания кости сводится к разжиганию костного мозга. Для этого требуются большие энергозатраты, которые зависят от техники разжигания. Однако мы пока не можем сказать, какой способ растопки самый эффективный. Теоретически возможно разжечь костер с одной кости, используя фитиль, воткнутый в костный мозг, но на практике нам этого не удалось. Использование древесной растопки остается оптимальным вариантом. Этот способ упрощает и ускоряет процесс. При сжигании большого объема костей объём требуемой древесной растопки может составлять ничтожные доли, в связи с чем древесный уголь может быть крайне сложно зафиксировать в очаге с костным углём. Поливание костей жиром, как это делали чукчи, вероятно, могло ускорить этот процесс разжигания или продлить горение (Крушанов, 1987, с. 78).

Перед первичным розжигом кости необходимо было высушить (удалить воду, сохраняя костный мозг) либо взять вымороженные кости, которые по предположению А. А. Чубу- ра хорошо горят (Чубур, 2018, с. 110-112). Затем в крупный костер уже можно добавлять и сырые. Поэтому вероятно, что исследователи будут находить больше осколков от сырых костей, поскольку сухие попадали в костер раньше, сгорали быстрее и превращались в золу.

Наблюдая, за горением трубчатых костей мы заметили, что разломанная пополам кость фактически представляет собой жирник (рис. 2). Возможно, такие наблюдения привели человека Верхнего Палеолита к созданию жировых ламп. В яме на памятнике Костёнки 1/1 был найден склад таких «ламп» из костей мамонта. Они служили для освещения помещений (Человек и мамонт..., 2019, с. 48).

Использование костного топлива является способом приспособления к экстремально холодному климату и не связано с культурной традицией. В качестве топлива должны использоваться кости с сохранившимся костным мозгом. Источниками костного топлива могли быть костища и добытые на охоте животные. Существовала практика отбора костей, наиболее пригодных для костра. Наличие источника костного топлива было важным критерием при выборе места для стоянки. Костный мозг, жир, содержащийся в костях, был основным топливом для охотников средней и поздней поры ВП, подобно тому, как китовый жир служил важнейшим топливом для северных охотников в XIX-XX веке.

\section{ЛИТЕРАТУРА}

Амирханов Х.А. Зарайская стоянка. М.: Научный мир, 2000. 243 с.

Амирханов Х.А., Ахметгалеева Н.Б., Бужилова А.П., Бурова Н.Д., Лев С.Ю., Мащенко Е.Н.. Исследования палеолита в Зарайске 1999-2005. М.: Палеограф 2009. 466 с.

Булочникова Е.В. Хронология верхнепалеолитических стоянок в Системе археологических и естественнонаучных данных // Хронология, периодизация и кросс-культурные связи в каменном веке. Замятнинский сборник. Вып. 1 / отв. ред. Г. А. Хлопачев. СПб.: Наука, 2008. С. 63-73.

Гаврилов К.Н. Структура Хотылевского верхнепалеолитического поселения // Восточный граветт / Отв. ред. Х. А. Амирханов. М.: Научный мир, 1998. С. 177-191.

Загорульский Э.М. Археология Беларуси. Минск: БГУ, 2001. 86 с. URL: https://arheologija.ru/ zagorulskiy-arheologiya-belarusi/ Дата обращения: 11.09.2020

История и культура ительменов: историко-этнографические очерки/ Под общ. ред. А. И. Крушанова. Л.: Наука, 1990. 208 с.

Crawford L.J. Woody fuel at Kostenki-1 // Стратегии жизнеобеспечения в каменном веке, прямые и косвенные свидетельства рыболовства и собирательства. Материалы международной конференции, посвященной 50-летию В.М. Лозовского. / Под ред. О.В. Лозовской, А.А. Выборнова, Е.В. Долбуновой. СПб.: ИИМК РАН, 2018. С. 249-251.

Крейнович E.А. Из жизни тундренных юкагиров на рубеже XIX и XX вв. // Страны и народы Востока. Вып. ХІІІ. Страны и народы бассейна Тихого океана. Книга 2. / Отв. ред. Ю.В. Маретин. М.: Наука, 1972. C. $56-92$. 
Крушанов А.И. История и культура чукчей Историко-этнографические очерки. Л.: Наука, 1987. $288 \mathrm{c}$.

Леонова Н.Б., Виноградова Е.А., Медведев С.П., Плохенко Б.Г. Многослойный памятник верхнего палеолита Северного Приазовья Каменная Балка II - история изучения и результаты исследований // Исторические исследования. 2015. № 3. С. 46-75. URL: http://www.historystudies.msu.ru/ojs2/index.php/ ISIS/article/view/45/128\#_ftnref14 Дата обращения: 11.09.2020

Мандро Н.М., Федоренко Т.В. Костный мозг, его состав и структура в сравнении у диких жвачных и сельскохозяйственных животных // Вестник КрасГАУ. 2013. №5. С. 181-183.

Торушев Э.Г. Некоторые кости животных в ритуалах алтайцев // Изучение историко-культурного наследия народов южной Сибири. Вып. 6. / Отв. ред. В.И. Соенов. Горно-Алтайск: АКИН, 2007а. C. $127-129$.

Файнберг Л.А. Охотники крайнего севера (индейцы и эскимосы). М.: Наука, 1991. 184 с.

Хлопачев Г.А. Юдиновская верхнепалеолитическая стоянка и ее значение для изучения поздней поры Верхнего палеолита бассейна р. Десны// Древние культуры Восточной Европы: эталонные памятники и опорные комплексы в контексте современных археологических исследований / Под ред. Г.А. Хлопачева. СПб.: МАЭ РАН, 2015. С. 128-149.

Человек и мамонт в палеолите Европы. Часть II: Днепро-Донская историко-культурная область. Памяти Михаила Васильевича Аниковича / Труды Костёнковско-Борщёвской археологической экспедиции ИИМК РАН. Вып. 8/II. / Отв. ред. С.Н. Лисицын, Н.И. Платонова. СПб.: Ars longa, 2019. 388 с.

Чубур А.А. Вновь о «мамонтовом собирательстве» Восточной Европы: новые факты, версии, и интерпретации // Стратегии жизнеобеспечения в каменном веке, прямые и косвенные свидетельства рыболовства и собирательства. Материалы международной научной конференции, посвященной 50-летию Владимира Михайловича Лозовского (Санкт-Петербург, 15-18 мая 2018 г.)/ Под ред.О.В. Лозовской, А.А. Выборнова и Е.В. Долбуновой СПб: ИИМК РАН, 2018. С. 110-112.

Sandrine Costamagno, Isabelle Thery-Parisot and other. Taphonomic consequences of the use of bones as fuel. Experimental data and archaeological applications // Proceedings of the $9^{\text {th }}$ Conference of the International Council of Archaeozoology. Durham, August 2002. URL: https://www.researchgate.net/ publication/261285317_Taphonomic_consequences_of_the_use_of_bones_as_fuel_Experimental_data_and_ archaeological_applicationsДата обращения: 11.09.2020

Sandrine Costamagno, Isabelle Thery-Parisot and other. Taphonomic impact of prolonged combustion on bones used as fuel Kesearchgate. 2010. URL: https://www.researchgate.net/publication/288906703 Taphonomic_impact_of_prolonged_combustion_on_bones_used_as_fuel Дата обращения: 11.09.2020

\section{Информация об авторах:}

Петровичева Таисия Олеговна, Государственный академический университет гуманитарных наук (г. Москва, Россия); pani.taisia@rambler.ru

Зубавичус Евгения Янович, Государственный академический университет гуманитарных наук (г. Москва, Россия); teremion@mail.ru

\section{REFERENCES}

Amirkhanov, Kh. A. 2000. Zarajskaya stoyanka (Zaraiskaya Site). Moscow: "Nauchny mir" Publ. (in Russian).

Amirkhanov, Kh. A., Akhmetgaleva, N. B., Buzhilova, A. P., Burova, N. D., Lev, S. Yu., Mashchenko, E. N. 2009. Issledovaniya paleolita v Zaraiske (Palaeolithic Studies in Zaraysk, 1999-2005). Moscow: "Paleograf" Publ. (in Russian).

Bulochnikova, E. V. 2008. In Khlopachev, G. A. (ed.). Khronologiia, periodizaciia i kross-kul'turnye svjazi v kamennom veke. (Chronology, Periodization and Cross-Cultural Relations in the Stone Age.). Series: Zamyatninskiy sbornik (Zamyatninsky Volume of Papers) 1. Saint Petersburg: "Nauka" Publ., 63-73 (in Russian).

Gavrilov, K. N. 1998. In Amirkhanov, Kh. A. (ed.). Vostochniy gravett (The eastern gravettian). Moscow: "Nauchny mir" Publ., 177-191 (in Russian).

Zagorul'ski, E. M. 2001. Arkheologiia Belarusi (Archaeology of Belarus) Minsk: Belarusian state University. Available at: URL: https://cyberleninka.ru/article/n/metallicheskie-zerkala-kak-predmet-vneshneyi-vnutrenney-torgovli-v-zolotoy-orde (accessed: 30.03.2020) (in Russian). 
Istorija i kul'tura itel'menov: istoriko-etnograficheskie ocherki ((History and Culture of the Itelmens: Historical and Ethnographic essays) In Krushanova, A. I. (ed.). 1990. Leningrad: "Nauka" (in Russian)

Crawford L.J. 2018. In Lozovsky, O. V., Vybornov, A. A., Dolbunova, E. V. (eds.). Strategii zhizneobespechenija $v$ kamennom veke, prjamye $i$ kosvennye svidetel'stva rybolovstva $i$ sobiratel'stva. (Subsistence Strategies In The Stone Age, Direct And Indirect Evidence Of Fishing And Gathering). Saint Petersburg: Institute of History of Material Culture, 249-251. (in English)

Kreinovich, E. A. 1972. In Maretin, Yu. V. (ed.). Strany i narody Vostoka. Vyp. XIII. Strany i narody bassejna Tihogo okeana. Kniga 2. (Countries and peoples of the East. Vol. XIII. Countries and peoples of the Pacific Basin. Book 2.). Moscow: "Nauka" Publ., 56-92 (in Russian)

Krushanov, A. I. 1987. Istoriia i kul'tura chukchei. Istoriko-etnograficheskie ocherki (History and Culture of the Chukchi. Historical and Ethnographic Essays.). Leningrad "Nauka" Publ. (in Russian).

Leonova, N. B., Vinogradova, E. A., Medvedev, S. P., Plokhenko, B. G. 2015. In Istoticheskie issledovaniia (Historical Studies). 3, 46-75 (in Russian).URL: http://www.historystudies.msu.ru/ojs2/index.php/ISIS/ article/view/45/128\#_ftnref14 (Accessed: 11.09.2020).

Madro, N. M. 2013. In Vestnik Krasnoyarskogo Gosudarstvennogo agrarnogo universiteta. (Bulletin of the Krasnoyarsk State Agrarian University) (5), 181-183 (in Russian).

Torushev, E. G. 2007. In Soenov, V. I. (ed.). Izuchenie istoriko-kul'turnogo naslediia narodov Iuzhnoi Sibiri (Study of the Historical and Cultural Heritage of the Peoples of Southern Siberia) 6. Gorno-Altaisk: "AKIN" Publ., 127-129 (in Russian).

Fainberg, L. A. 1991. Ohotniki krajnego severa (indejcy i jeskimosy). (Hunters of the Far North (Indians and Eskimos)). Moscow: "Nauka" Publ. (in Russian).

Khlopachev, G. A. 2015. In Khlopachev, G. A. (ed.). Drevnie kul'tury Vostochnoj Evropy: etalonnye pamjatniki i opornye kompleksy $v$ kontekste sovremennyh arheologicheskih issledovanij (Ancient Cultures of Eastern Europe: Reference Sites and Support Complexes in the Context of Contemporary Archaeological Studies). Saint Petersburg: Peter the Great Museum of Anthropology and Ethnography (Kunstkamera) of Russian Academy of Sciences, 128-149 (in Russian).

Man and Mammoth in the Paleolithic of Europe. Part II: Dnieper-Don Historical and Cultural Habitat. 2019. In Lisitsyn, S. N., Platonova, N. I. (eds.). Saint Petersburg: Ars Longa Publishing House (in Russian).

Chubur, A. A. 2018. In Lozovskaya, O. V., Vybornov, A. A., Dolbunova, E. V. (eds.). Strategii zhizneobespecheniia v kamennom veke, priamye i kosvennye svidetel'stva rybolovstva i sobiratel'stva. Materialy mezhdunarodnoj nauchnoj konferencii, posvjashhennoj 50-letiju Vladimira Mihajlovicha Lozovskogo (Sustenance Strategies in the Stone Age, Direct and Indirect Evidence of Fishing and Gathering. Proceedings of the International Scientific Conference dedicated to the 50th Anniversary of Vladimir Mikhailovich Lozovsky). Saint Petersburg: Institute of History of Material Culture, 110-112 (in Russian).

Sandrine Costamagno, Isabelle Thery-Parisot and other. 2002. Taphonomic consequences of the use of bones as fuel. Experimental data and archaeological applications. Proceedings of the 9th Conference of the International Council of Archaeozoology. Durham, August 2002. Available at: https://www.researchgate.net/ publication/261285317_Taphonomic_consequences_of_the_use_of_bones_as_fuel_Experimental_data_and_ archaeological_applications (accessed 11.09.2020)

Sandrine Costamagno, Isabelle Thery-Parisot and other. 2010. Taphonomic impact of prolonged combustion on bones used as fuel Kesearchgate. Available at: https://www.researchgate.net/publication/288906703 Taphonomic_impact_of_prolonged_combustion_on_bones_used_as_fuel (accessed 11.09.2020)

\section{About the Authors:}

Petrovicheva Taisiya O. State Academic University of Humanities. Maronovskiy pereulok, 26, Moscow, 119049, Russian Federation; pani.taisia@rambler.ru

Zubavichus Evgeniya Ya. State Academic University of Humanities. Maronovskiy pereulok, 26, Moscow, 119049, Russian Federation; Teremion@mail.ru 


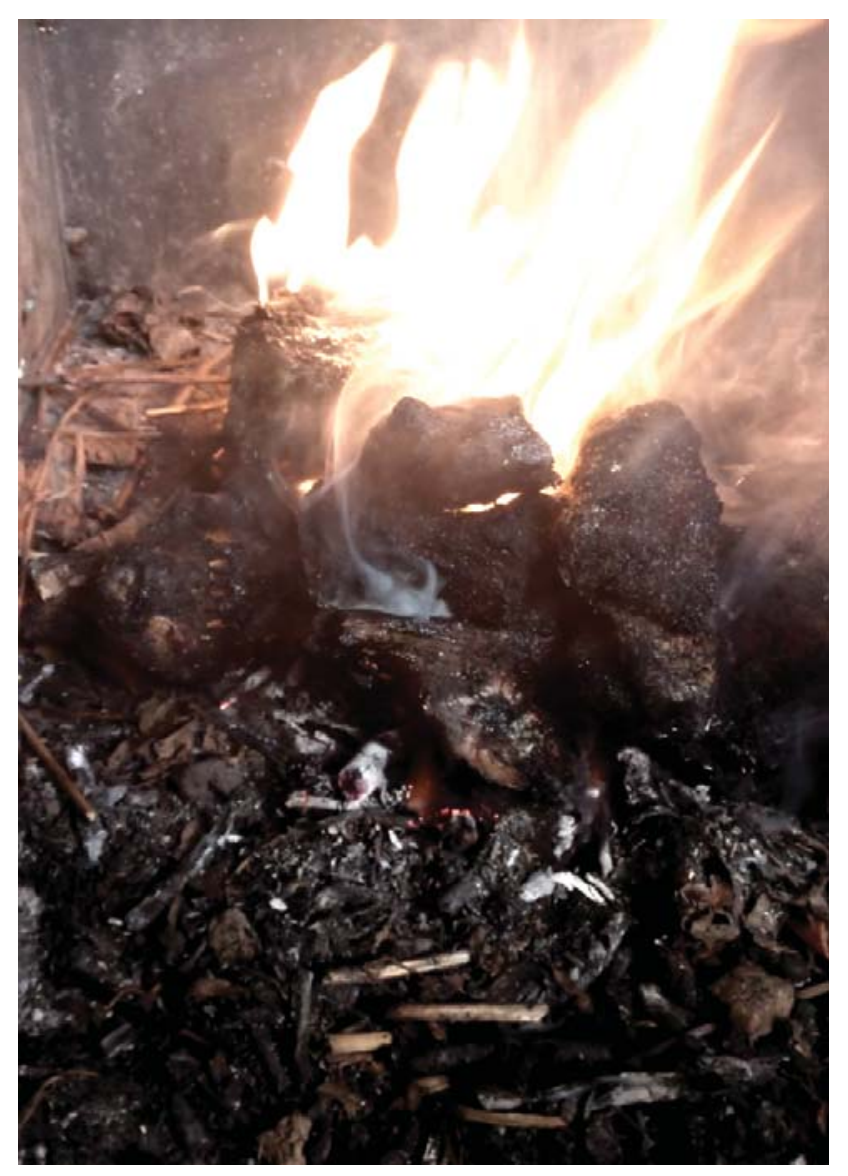

Рис. 1. Горение костяного костра (без древесины)

Fig 1. Burning of a bone fire (with no wood)

Рис. 2. Жирник из половины трубчатой кости Fig 2. Oil lamp made of a half of a tubular bone

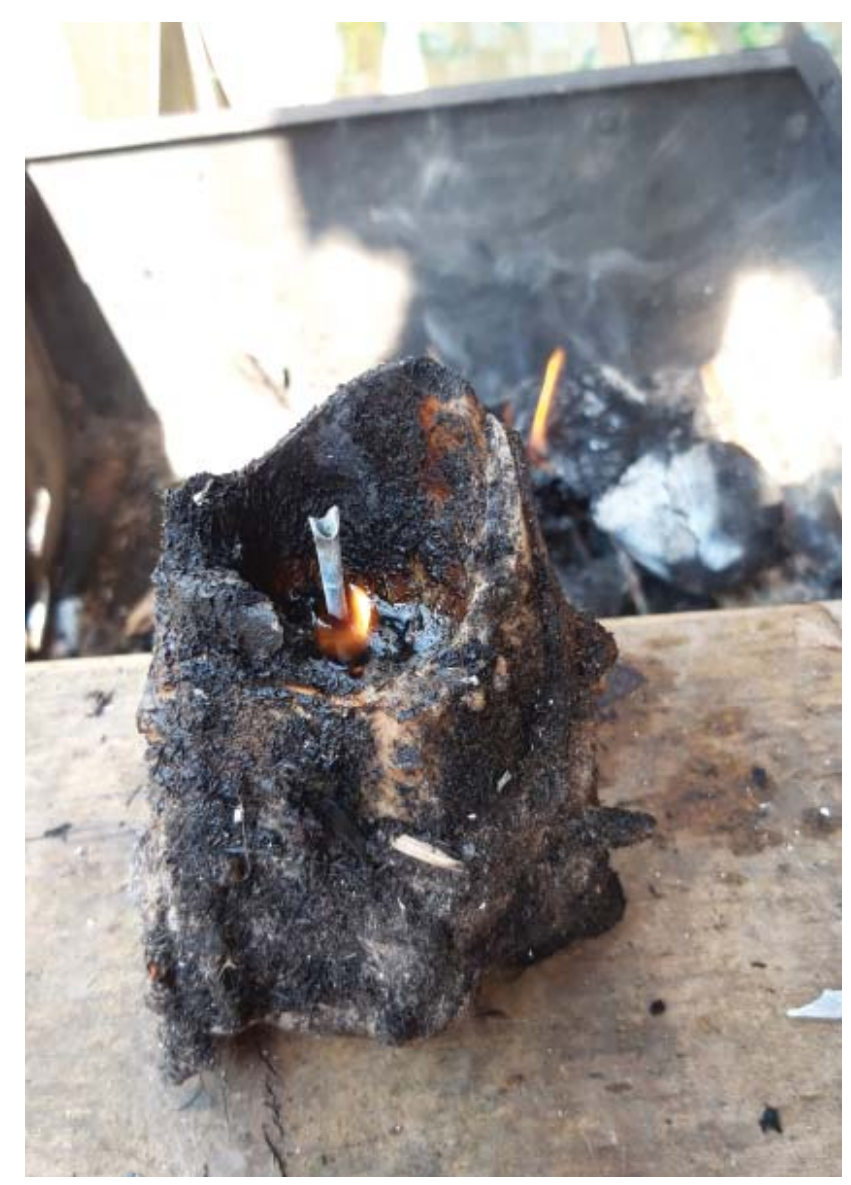

